\section{Commentary: The right fit: If you cannot find it, make it.}

\author{
Gita N. Mody, MD, MPH
}

Size reduction of donor lungs including lobectomy, segmentectomy, and peripheral wedges has been part of armamentarium of lung transplant surgeons looking for "the right fit" since the mid-1990s. ${ }^{1,2}$ The technique and outcomes of pulmonary reduction of various forms have been well described. ${ }^{3}$ Centers with specialized transplant expertise including for children ${ }^{4}$ and with living donors ${ }^{5}$ have published extensively on their lobar lung transplant approach. However, understanding the role of lobar lung transplantation from deceased donors in routine practice remains a priority, to facilitate expansion of the technique and consequentially shrinkage of the wait list, particularly for small or fibrotic patients.

Establishing the clinical efficacy of lobar transplantation is a challenge, owing to the relative rarity of the procedure due to the technical requirements to adjust for the caliber of the airway and arterial anastomoses and hesitancy to accept reduced postoperative pulmonary function. The inherent risk factors of recipients who ultimately undergo this procedure, including their urgency, also must be considered when evaluating results. Previous large single-center experience comparing cadaveric lobar with standard lung transplantation reported worse short-term outcomes in the lobar-reduction group, although 5-year postdischarge survival was equivalent. ${ }^{6}$ Other published literature demonstrates equivocal results largely due to the heterogeneity of approaches to selecting recipients for lobar reduction.

Now, Schiavon and colleagues ${ }^{8}$ have provided an analysis of a relatively large retrospective cohort from 2 Italian centers using propensity score weighting of important

\footnotetext{
From the Division of Cardiothoracic Surgery, Department of Surgery, The University of North Carolina at Chapel Hill, Chapel Hill, NC.

Disclosures: Dr Mody reported an unpaid consulting role with Sivan Ltd for unrelated work and research funding from American College of Surgeons for unrelated work.

The Journal policy requires editors and reviewers to disclose conflicts of interest and to decline handling or reviewing manuscripts for which they may have a conflict of interest. The editors and reviewers of this article have no conflicts of interest.

Received for publication Aug 24, 2021; revisions received Aug 24, 2021; accepted for publication Aug 24, 2021; available ahead of print Aug 30, 2021.

Address for reprints: Gita N. Mody, MD, MPH, Department of Surgery, The University of North Carolina at Chapel Hill, 4001 Burnett-Womack Building, Chapel Hill, NC 27599-7050 (E-mail: gita_mody@med.unc.edu).

J Thorac Cardiovasc Surg 2022;164:297-8

$0022-5223 / \$ 36.00$

Copyright (c) 2021 by The American Association for Thoracic Surgery

https://doi.org/10.1016/j.jtcvs.2021.08.056
}

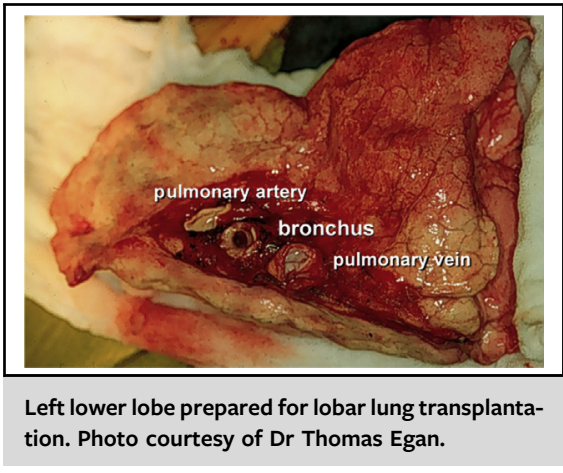

CENTRAL MESSAGE

Lobar lung transplantation is safe and effective. More routine use in selected patients may allow increased experience and improved outcomes.

recipient and donor risk factors to compare lobar and standard lung transplant outcomes. The results make intuitive sense: there is an increase in early primary graft dysfunction (T0 grade 3 primary graft dysfunction) and slight reduction in postoperative pulmonary function but noninferior shortand long-term survival in patients selected by experienced surgeons for lobar reduction (due to elevated recipient/ donor total lung capacity ratio). Notably, airway complication rates and management were similar in both groups. While propensity score methods cannot fully account for the differences in patients selected for lobar transplantation, they mitigate the effects of confounding through appropriate statistical adjustments by including observed patient characteristics in both groups when comparing treatment effects. In the absence of being able to perform a randomized controlled trial, these observational study results support the use of lobar reduction for size mismatch in lung transplant recipients.

We are now faced with the difficulty of knowing how and when to implement the cadaveric lobar lung transplantation technique more routinely. If reserved for urgency due to acuity of initial presentation or waitlist deterioration, experience is likely to remain low and outcomes may appear worse. If employed more standardly in patients with anticipated difficult matches due to their stature, thoracic cavity size, blood type, and/or antibodies, waitlist time and therefore outcomes may be improved. Future prospective studies will be required to demonstrate the impact of cadaveric 
lobar lung transplantation on both clinical and health services outcomes.

\section{References}

1. Bisson A, Bonnette P, el Kadi NB, Leroy M, Colchen A. Bilateral pulmonary lobe transplantation: left lower and right middle and lower lobes. Ann Thorac Surg. 1994;57:219-21.

2. Egan TM, Thompson JT, Detterbeck FC, Lackner RP, Mill MR, Ogden WD, et al. Effect of size (mis)matching in clinical double-lung transplantation. Transplantation. 1995;59:707-13.

3. Aigner C, Winkler G, Jaksch P, Ankersmit J, Marta G, Taghavi S, et al. Sizereduced lung transplantation: an advanced operative strategy to alleviate donor organ shortage. Transplant Proc. 2004;36:2801-5.
4. Starnes VA, Barr ML, Cohen RG. Lobar transplantation. indications, technique and outcome. J Thorac Cardiovasc Surg. 1994;108:403-10; discussion 410.

5. Date H, Aoyama A, Hijiya K, Motoyama H, Handa T, Kinoshita H, et al. Outcomes of various transplant procedures (single, sparing, inverted) in livingdonor lobar lung transplantation. J Thorac Cardiovasc Surg. 2017;153:479-86.

6. Slama A, Ghanim B, Klikovits T, Scheed A, Hoda MA, Hoetzenecker K, et al. Lobar lung transplantation-is it comparable with standard lung transplantation? Transpl Int. 2014;27:909-16.

7. Eberlein M, Reed RM, Chahla M, Bolukbas S, Blevins A, Van Raemdonck D, et al. Lobar lung transplantation from deceased donors: a systematic review. World $J$ Transplant. 2017;7:70-80.

8. Schiavon M, Mendogni P, Faccioli E, Lorenzoni G, Mazzucco A, Nosotti M, et al. Lobar size reduction in lung transplantation: a propensity score study. $J$ Thorac Cardiovasc Surg. 2022;164:289-96.e2.
See Article page 289.

\section{Commentary: Better too big than too small}

\section{Hiroshi Date, MD}

In this issue of the Journal, Schiavon and colleagues ${ }^{1}$ reported a 2-institution retrospective study to assess earlyand long-term outcomes associated with lobar reduction in lung transplantation for adult small recipients. The propensity score was estimated on 571 patients (522 in group $\mathrm{I}=$ no lobar reduction, and 49 in group II $=$ lobar reduction). Although group II showed worse long-term pulmonary function, the 2 groups had comparable survival outcomes. Compared with standard lung transplantation, lobar lung transplantation requires more careful intraoperative judgements and is more technically demanding. Therefore, lobar lung transplantation should be performed by experienced surgeons. The authors are to be congratulated for completing this important study.

The most difficult and important part of lobar transplantation is how to make a final call for lobar reduction. Small recipients include small-height recipients with normal chest configuration and recipients with small chest cavities due to

From the Department of Thoracic Surgery, Graduate School of Medicine, Kyoto University, Kyoto, Japan.

Disclosures: The author reported no conflicts of interest.

The Journal policy requires editors and reviewers to disclose conflicts of interest and to decline handling or reviewing manuscripts for which they may have a conflict of interest. The editors and reviewers of this article have no conflicts of interest.

Received for publication Aug 29, 2021; revisions received Aug 29, 2021; accepted for publication Aug 31, 2021; available ahead of print Sept 4, 2021.

Address for reprints: Hiroshi Date, MD, Department of Thoracic Surgery, Graduate School of Medicine, Kyoto University, 54 Kawahara-cho, Shogoin, Sakyo-ku, Kyoto 606-8507, Japan (E-mail: hdate@kuhp.kyoto-u.ac.jp).

J Thorac Cardiovasc Surg 2022;164:298-9

$0022-5223 / \$ 36.00$

Copyright (c) 2021 by The American Association for Thoracic Surgery

https://doi.org/10.1016/j.jtcvs.2021.08.073

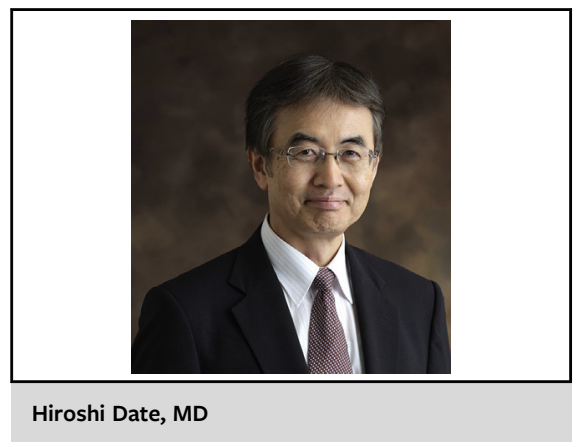

CENTRAL MESSAGE

Lobar lung transplantation provides similar survival to standard lung transplantation for small patients.

flat chest and/or elevated diaphragm. As the authors state, donor-to-recipient predicted total lung capacity and heights ratio are useful for recipients with normal chest cavity but may not be useful for recipients with a flat chest. For the latter recipients, an "eyeball evaluation" by experienced surgeons during the transplant procedure is essential.

Living-donor lobar lung transplantation (LDLLT) is indicated for patients considered too ill to await cadaveric lung transplantation. ${ }^{2}$ In LDLLT, the right and left lower lobes are removed from 2 healthy donors and these 2 lobes are implanted in the recipient as whole right and left lungs. LDLLT is technically similar to lobar reduction cadaveric lung transplantation for a small recipient. Having done more than 150 LDLLTs, I believe lower lobe implantation works well because of the similar shape between the graft 